En el presente trabajo nos centraremos en una caracteristica observada con frecuencia en las traducciones de Literatura Infantil y Juvenil (LIJ): el paternalismo traductor. Dicho comportamiento de los mediadores se puede apreciar tanto en traducciones literarias como audiovisuales para niños y jóvenes. A partir del estudio descriptivo de varios casos que nos permitirán demostrar la elevada frecuencia de conductas paternalistas en la traducción de LIJ, trataremos de establecer una tipología del concepto que podría ser perfeccionada en posteriores estudios con corpora más amplios.

PALABRAS CLAVE: traducción del género infantil y juvenil, manipulación en traducción, paternalismo traductor, Estudios Descriptivos de Traducción

\title{
Paternalismo traductor en las traducciones del género infantil y juvenil
}

LOURDES LORENZO

Universidad de Vigo

\section{Paternalistic behaviour in children's literature translations}

The aim of this article is to study a translation feature frequently observed in translations for children and young people that can be called "translator paternalism". Such a behaviour can be witnessed not only in literary translations but also in screen translations. With the description of several case studies the goal of this article is to prove the high frequency of paternalistic trends when translating for children and young people and to propose a typology which could be later improved in future approaches comprising larger corpora of translations.

KEY WORDS: translations for children and young people, manipulation in translation, paternalism in translation, Descriptive Translation Studies 


\section{INTRODUCCIÓN}

Cuando hace unas décadas los primeros ${ }^{\mathrm{T}}$ estu- $^{-}$ diosos de la traducción de Literatura infantil y juvenil (LIJ) se asomaban a ella lo hacían desde una perspectiva básicamente didáctica e inscrita en el paradigma de fidelidad al texto origen (то) que imperaba por aquel entonces (Klingberg, I978). Las investigaciones que siguieron después, ancladas en dos paradigmas básicos (funcionalismo y teorías polisistémicas), superaron esta visión limitada y recondujeron el enfoque al partir ya no del hecho literario sino del propio género (productos infantiles y juveniles), que podía desarrollarse en distintos formatos, especialmente en dos: literarios y audiovisuales.

Así, partiendo de reflexiones teóricas y múltiples estudios de caso, permitieron que en el momento presente dispongamos de un catálogo bastante completo tanto de las características del género infantil y juvenil como del comportamiento traductor y las estrategias de los mediadores.

No pretendemos aquí ofrecer dicho catálogo, sino centrarnos en una característica del comportamiento traductor que, aunque muy repeti$\mathrm{da}$, no por ello ha sido hasta el momento igual de estudiada: el paternalismo de los traductores. Para ello partiremos de una definición de lo que entendemos por "paternalismo», presentaremos unos cuantos estudios de caso que nos permitirán demostrar la elevada frecuencia con

Cuando nos referimos a «los primeros estudiosos de la traducción de LIJ» lo hacemos considerando que ellos -Klingberg (1978, I986), Toury (1980, I995), Zohar-Shavit (1979, 1997), Shavit (2006), Pascua (1998, 2003, 20II) o Fernández López (1996, 2000)- han sido pioneros en analizar profundamente el campo. Tal como indica Lathey (2006), el deseo explícito de tomar parte activa en las traducciones de LIJ ya había sido objeto de reflexión a finales del siglo XVIII y términos como «naturalización» eran utilizado por Wollstonecraft en esa misma época. 
el caso de LIJ - o directores de doblaje — en el caso de la traducción de productos audiovisuales para niños y jóvenes). ${ }^{4}$

Pero no se trata aquí de inventar la rueda, 5 ya que el propio Klingberg (1986) se refería de alguna manera al paternalismo cuando hablaba de las "purificaciones» en la LIJ y en su traducción, esto es, un proteccionismo exacerbado que no deja espacio para temas como la muerte, el sexo o la violencia. En esta misma línea Oitinnen (2005: II3) indica que ciertos temas se purifican, lo que lleva a que por ejemplo el alcohol en las obras de LIJ se sustituya por frutas, leche o miel. Ni que decir tiene que este tipo de paternalismos temáticos llega a su máxima expresión cuando se traduce en contextos musulmanes (Aziz, 20Io).

Lo que pretendemos es recuperar este tema y ampliar sus márgenes, ya que en él tienen cabida no sólo la censura temática a la que se refería el estudioso sueco sino toda aquella decisión del traductor que tenga que ver con la simplificación del texto para acercarlo a las capacidades comprensivas del potencial público receptor. ${ }^{6}$

4 Gómez Pato (2012: 249-250) ofrece un ejemplo muy interesante de censura editorial en la traducción gallega de Das Austauschkind (Ch. Nöstlinger, I998); mientras que las ilustraciones originales mostraban sin reparo el órgano sexual del protagonista, las ilustraciones de la traducción gallega ofrecían al protagonista de espaldas, de tal manera que dicho órgano quedaba oculto a los ojos de los lectores.

5 Eso lo dejamos para otros colegas más preocupados por la génesis de nueva terminología para temas tratados desde siempre en traducción (cfr. la crítica realizada al concepto de paratraducción por Ch. Nord en su artículo en Perspectives. Studies in Translatology, «Paratranslation - a new paradigma or a re-invented wheel?», 2012).

6 Hace ya tiempo que hay consenso generalizado en que los productos del género infantil-juvenil (literatura y formatos audiovisuales fundamentalmente) son productos de doble receptor niño-adulto (Ruzicka, I995; Zabalbeascoa, 2000; Oittinen, 2006); pero en cualquier caso, el niño y el joven son los receptores primarios.

\section{TIPOS DE PATERNALISMO}

Teniendo en cuenta todo lo dicho anteriormente, podemos hablar de dos tipos básicos de conductas paternalistas:

\section{I. Paternalismos omisores}

En términos polisistémicos7, pueden ser resultado de la aplicación de una norma preliminar (decisiones de una editorial de no traducir determinados libros) o darse a nivel de normas operacionales (supresión de elementos considerados dañinos u ofensivos en la propia traducción por el traductor o en el proceso de revisión por editores ${ }^{8}$, en el caso de la LIJ, o por ajustadores, directores de doblaje o supervisores -jefes de tráfico- de subtítulos, en el caso de productos audiovisuales).

A veces libros considerados «peligrosos» nunca llegan a traducirse (o lo hacen mucho más tarde que los To correspondientes). Esto es lo que ha ocurrido con dos obras de LIJ publicadas en r994 en Alemania (Leanders Traum, de Doris Meissner-Johannknecht y Papas Freund, de Michael Willhoite); su excelente acogida en la CO no tuvo correspondencia en España, probablemente porque los editores temían el rechazo del público por su temática homosexual. ${ }^{9}$

A nivel de normas operacionales (estrategias traslativas dentro del texto) ya Miller (2003) hablaba de los traductores como filtros sociopolíticos cuando en las traducciones inglesas de Julio Verne suprimían determinados pasajes que afeaban el imperialismo británico y su actuación

7 Cfr. Toury (I980: 53-54; 1995: 56-6I) para la revisión del concepto y tipología de normas de traducción.

8 Estos revisores también podrían identificarse con los propios censores en el caso de regímenes dictatoriales, como ha ocurrido en las traducciones realizadas en España durante el franquismo. Para profundizar en este tema dentro del campo de la LIJ, cfr. Pascua (20II).

9 Cfr. Ruzicka y Lorenzo (2008). 
poco decorosa en la India o cuando uno de estos traductores (Lewis, que formaba parte del clero) eliminó de su traducción cualquier referencia que el To hacía a Darwin ${ }^{\text {Io }}$.

\subsection{Paternalismos explicativos}

Este tipo de conductas paternalistas tienen como objetivo facilitar la comprensión de los textos a aquellos receptores que por edad o discapacidad tienen habilidades lingüísticas y un «conocimiento de mundo» más limitados. Dentro de ellas podemos diferenciar varios tipos:

\subsection{Inclusión de paratextos}

Notas a pie o glosarios constituyen fórmulas explicativas de uso frecuente en las traducciones cuando se quiere facilitar la comprensión de un concepto, un juego de palabras, etc. del To. Como indica Marrero (200r: 84), las notas a pie de página «configuran, como actos realizados por el traductor, una dimensión pragmática reparadora de las dificultades de entendimiento y de cooperación de receptores de otras lenguas y culturas, al operar éstos en entornos cognitivos diferentes». Así, por ejemplo, las traducciones al catalán, euskera y español de $A$ Study in Scarlet (Conan Doyle, r887) contienen abundantes notas de los traductores (hasta 40 en la traducción española) para explicar a los jóvenes referentes culturales, etcétera. ${ }^{\mathrm{II}}$

\subsubsection{Explicaciones intratextuales}

En ocasiones y con el fin de no interrumpir la lectura de un texto, se incluyen en la propia traducción paráfrasis explicativas, adjetivos

ro Cfr. Ruzicka y Lorenzo (2005) para una revisión pormenorizada de estos ejemplos. Véase también el trabajo de Lorenzo y Pereira (2000) sobre la traducción de una obra de Roald Dahl si se quiere observar otro caso de paternalismo omisor a nivel de normas operacionales.

II Cfr. Ruzicka y Lorenzo (2003) para otros ejemplos de notas a pie introducidas por los traductores. clarificadores, etc. de un determinado concepto. Esto es lo que ocurre cuando Paula Pintos, la traductora al gallego de la obra de Kaye Umansky Pongrwiffy and the Goblins' Revenge, 199I (Fedorenta e a vinganza dos trasnos, 2007) decide incluir una explicación aproximada en su traducción del término «tartan»:

[contexto: se describe la escoba de McAbra, la bruja escocesa]

TO: Witch Macabre, whose extra-long tartan painted $^{\text {12 }}$ Broomstick had to be reinforced so that it could carry the combined weight of herself, her bagpipes and her Haggis, whose name was Rory. (p.55)

TM: Logo chegou a meiga McAbra, que tivera que reforzar a súa vasoira (pintada con motivos que recordaban aos da tea escocesa) para que aturase o seu peso, o da súa gaita e mais o do seu haggis (que se chamaba Rory). (p.42)

Aunque el término «tartán» existe también en español y gallego, no es una palabra de uso común ${ }^{13}$ así que la traductora decide explicar su significado entre paréntesis. Lo que cabría preguntarse es: ¿los pequeños lectores del To reconocerían el término? ¿El hecho de que la cultura escocesa esté integrada dentro del macrocontexto anglosajón podría apuntar a una mayor facilidad de decodificación del término?

Algo similar acontece cuando se introduce un adjetivo como pista para que los receptores reparen en la intertextualidad subyacente a la reescritura feminista de la historia de Blancanieves (Anholt, L., 2002. Snow White and the

I2 Todas las negrillas de los ejemplos se han añadido para facilitar la localización de lo que se está comentando.

13 CREA (Corpus de Referencia del Español Actual)

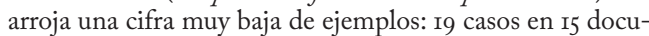
mentos. En corgA (Corpus de Referencia do Galego Actual) la situación se repite: sólo 3 casos en 3 documentos y con vacilación en el acento («tartan»/«tartán»). 
Seven Aliens, London: Orchard Books):

[Contexto: Blancanieves está a punto de debutar como cantante pop con la banda de los Siete Alienígenas. En el escenario la paraliza el miedo escénico y la banda teme tener que recurrir a temas antiguos para salir del paso]

To: "It's no use," bawled Botty. "We'll have to sing 'hi ho, hi ho...'” (p.34)

TM: «No hay nada que hacer», gimió Botty. «Tendremos que cantar el viejo ai vo, ai vo...» (p.4I)

Con la introducción del adjetivo «viejo» se intenta que el receptor recuerde fácilmente que la canción de los Siete Alienígenas remite a la canción previa de los siete enanitos. Se trata, pues, de una conducta paternalista del traductor con el fin de facilitar el reconocimiento del eco intertextual.

\subsubsection{Explicitación en el TM de elementos implícitos en el TO}

A veces el autor del To confía (o, simplemente, puede que no se haya parado a pensarlo) en que los receptores de su obra entiendan determinadas alusiones, convenciones tipográficas, etc. En la misma obra mencionada anteriormente, Kaye Umansky echa mano de personajes de obras literarias que considera conocidos por los niños del sistema lingüístico-cultural anglosajón ${ }^{14}$ para indicar de qué se disfrazarán las brujas en el concurso de Hallowe'en: tenemos disfraces de Juana de Arco o de la Bella Durmiente (Joan of Arc / Sleepy Beauty en TO y Xoana de Arco / a bela durminte en TM) pero también disfraces de algunos personajes a los que la autora no presenta de forma tan directa: Happy the

I4 Hablamos de sistema lingüístico-cultural anglosajón para referirnos al polisistema que comprende la lengua inglesa y sus variantes geográficas y la cultura inglesa, norteamericana, australiana y canadiense básicamente.
Dwarf / The Witches on the Blasted Heath / The Good Witch Glinda / The Sweet House Witch. En estos casos la traductora explicita dichos elementos, con soluciones como: Feliz, o ananiño de Brancaneves / As meigas de Hamlet 15 / A meiga boa do sur de $O$ mago de $\mathrm{Oz} / \mathrm{A}$ meiga da casiña de chocolate de Hansel e Gretel.

También en esta obra la autora presenta mediante una interrogación entre paréntesis el asombro que transmite el extraño «complemento» que uno de los personajes lleva en la cabeza:

[CONTEXTo: se están describiendo los personajes que participan en el asalto a un basurero]

TO: A sinister figure with a paper bag over his head (?) (p.58)

TM: Unha figura sinistra cunha bolsa de papel na cabeza (a conto de que?) (p.45)

Como podemos apreciar, la traductora cree oportuno explicitar el contenido aludido por dicha interrogación (¿a cuento de qué la llevaba en la cabeza? ¿Para qué la llevaba?).

\subsubsection{Sustitución de un elemento por otro}

Cuando se considera que determinado elemento (un referente cultural o intertextual, un hipónimo, etc.) del To puede no ser comprendido por los niños se sustituye por otro del que se presupone conocimiento general. Este afán simplificador que busca adaptar la historia a las capacidades cognitivas de los niños se registra en el comportamiento de muchos traductores y también es alabado por teóricos y estudiosos del género (Lefevere, 1992; Fernández López, 1996; Fischer, 2000; Shavit, 2009; Lathey, 2010). A este respecto, Pascua (200I: 43) indica:

I5 La traductora ha confundido la obra de referencia. Las susodichas brujas pertenecen a Macbeth, no a Hamlet. 
Si consideramos que un texto meta debe ser aceptable y aceptado por los pequeños lectores, el traductor debe realizar todos los cambios que considere oportunos, cuando supone que al niño le faltan una serie de conocimientos que por su poca experiencia no posee [...] No podemos defraudarlo ni ir en contra de sus expectativas, dejando en el nuevo texto referencias que él no entiende, lo cual no quiere decir que no ampliemos sus horizontes y sus conocimientos de esas otras realidades $[\ldots]$

Un ejemplo de estas sustituciones lo tenemos cuando (en la misma obra estudiada anteriormente) la traductora decide reemplazar el animal mencionado en el To por otro que considera más fácil de reconocer por los pequeños lectores de su traducción:

[CONTEXTO: las brujas están pensando en disfraces para la fiesta]

To: We could dress up as Stone age cavewomen if we liked. In sabre-toothed tiger skins. (p. 69)

TM: [...], podemos disfrazarnos como trogloditas, se queremos. Con pelo de mamut e todo. (p.73)

Semejante situación tenemos en la siguiente escena de Lady and the Tramp (Joe Grant, I955) y en su doblaje español (La dama y el vagabundo):

[CONTEXTO: el castor se disculpa por no poder dejar sus quehaceres cotidianos para acudir en la ayuda de Reina y roerle el bozal que le han puesto]

BEAVER: [struggling with a log] Ah-ah-ah, busy sonny, busy! Gotta slide this sycamore to the - ung - swamp!

CAstor: No, hijo. Estoy muy ocupado. No puedo detenerme a charlar. Debo empujar este tronco hasta el río...
En la traducción para doblaje se considera que el hipónimo inglés «sicomore» será difícil de comprender por los niños y se sustituye por el término común más habitual («tronco»).

Dentro de esta categoría incluiríamos también aquellos referentes propios de la cultura origen ( $\mathrm{CO}$ ) que han sido neutralizados o sustituidos por otros compartidos por las dos culturas en contacto. Así, en la traducción para doblaje de Pocahontas (Mike Gabriel y Eric Goldberg, I995) se evita el nombre del rey inglés (a), aunque esto provoque una pequeña incoherencia más adelante $(\mathrm{b})$ :

(a) [CONTEXTo: Ratcliffe cuenta a su ayudante el agradable futuro que le aguarda una vez haya conseguido el oro]

TO: I'm very well aware that this is my last chance for glory. But mark my words, Wiggins, when King James see the gold these peasants unearth success will be mine, at last.

тм: Fíjate lo que te digo, Wiggins, cuando el rey vea el oro que esos patanes me van a encontrar, ese día habré alcanzado el éxito.

(b) [contexto: Ratcliffe bautiza el nuevo enclave con el nombre del rey]

то: I hereby Chaim this land and all its riches in the name of His Majesty King James the first, and do so name this settlement Jamestown.

TM: Reclamo aquí esta tierra y todas sus riquezas en nombre de su majestad, el rey de Inglaterra. Llamaré a esta nueva colonia Jamestown.

Como se puede apreciar, en el TM no hay conexión directa (como sí existe en el TO) entre la denominación de la colonia y el nombre del rey.

Otra estrategia neutralizadora es la escogida para la siguiente referencia overt (Rabadán, I99I; 
Shuttleworth y Cowie, 1997) por la traductora de Pongrwiffy and the Goblins' Revenge:

[Contexto: las brujas se disponen a ir a pedirle explicaciones al genio]

TO: “Tallyho!" shrieked Sourmuddle as her Broomstick plunged and reared, as overexcited as a highly-strung race horse" (p.35)

TM: "Adianteee! -bradou Caprichocha mentres a vasoira daba tombos adiante e atrás, como un cabalo encabuxado." (p.44)

«Tallyho» es la palabra británica utilizada en la caza del zorro, tan popular en el Reino Unido, cuando el jinete divisa al animal. El probable desconocimiento de dicho referente por parte de la gran mayoría de pequeños receptores de la traducción lleva a que se neutralice este elemento.

Por otro lado, la traductora del libro busca el elemento compartido cuando, en el momento de nombrar los disfraces de las brujas, sustituye aquellos correspondientes a personajes del contexto literario anglosajón por otros reconocibles tanto en la CO como en la CM: Little Bo Peep deja paso a a aboa de Carapuchiña Vermella y Tweedledee and Tweedledum se diluyen y $O$ gordo e o fraco ocupan su lugar en el TM.

Aunque estos intervencionismos ${ }^{16}$ pueden

16 E1 término intervencionismo es sinónimo de manipulación, pero lo preferimos por la ausencia de carga peyorativa en él. El traductor interviene en los textos por razones varias, que van desde la búsqueda de aceptabilidad para su traducción en la CM (censura, paternalismo...), a la necesidad de resolver determinados problemas lingüísticos, culturales o pragmáticos (juegos de palabras...), pasando por razones de corte ideológico como las que veremos en el apartado 3.2.6., etc. (Lorenzo y Pereira, 200o; Lorenzo, 2003; Marcelo, 2003). Los intervencionismos son especialmente abundantes en la LIJ (Oittinen, 2006), aunque no sólo para adecuarse a las características del público meta (Hatim y Mason, I997; Nord I997), tal como vemos en el presente trabajo. considerarse bastante efectivos en términos de comprensión en la $\mathrm{CM}$, hay una referencia que merece reflexión: Tweedledee y Tweedledum (personajes de Through the Looking Glass, de Lewis Carroll) se han traducido con frecuencia al español como Patachunta y Patachún. Sin embargo, probablemente Patachunta y Patachún son tan opacos para los niños de hoy como el gordo y el flaco.

Como indicábamos en la introducción y en el segundo apartado, este tipo de sustituciones motivadas por las dudas que tiene el traductor (editor, director de doblaje, etc.) sobre el reconocimiento de un referente del TO por parte de los pequeños receptores no se circunscriben al ámbito de la traducción de LIJ sino que también son muy frecuentes en la traducción de productos audiovisuales de doble receptor adulto-niño. El siguiente ejemplo extraído de Shrek (Adamson y Jenson, 20or) y de su doblaje al español puede ilustrar esta afirmación:

[CONTEXTo: Asno está muy nervioso porque a Shrek le han clavado una flecha y piensa que va a morir]

To: I'm too young for you to die. Keep your legs elevated. Turn your head and cough.

Does anyone know the Heimlich?

TM: No me hagas esto. Soy muy joven para que mueras. Las piernas en alto. Di treinta y tres. $i$ Que alguien le haga un torniquete!

Aunque la maniobra de compresión abdominal en caso de ahogamiento no se puede decir que sea exclusiva de la co y de que dicha técnica también sea conocida como «maniobra de Heimlich» en la CM, los mediadores no confían en que sea comprensible por niños y jóvenes y recurren a una referencia al torniquete, mucho más fácil de reconocer. Se trata, así de un equivalente funcional dado que sí sirve para 


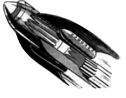

42
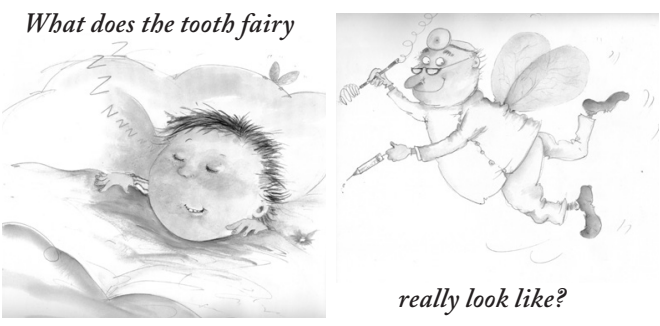

really look like?
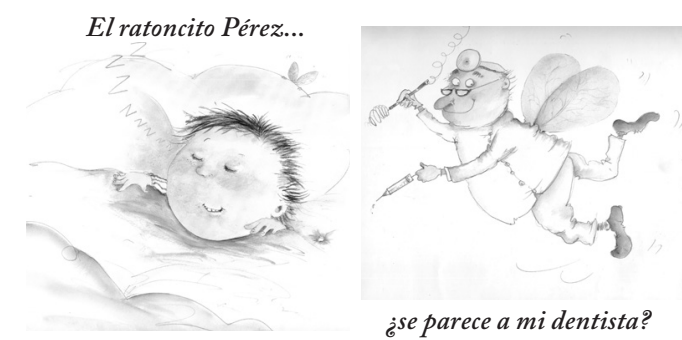

¿̇se parece a mi dentista?

Figura I

recrear la escena con sus claves básicas: Asno está muy nervioso y empieza a enunciar todas las técnicas médicas y de primeros auxilios que se le ocurren. Una vez más se rebaja el nivel de dificultad para facilitar la comprensión del TM; y de nuevo podríamos preguntarnos lo mismo que ante el ejemplo presentado en el apartado 3.2.2.: ¿hasta qué punto es reconocible dicha maniobra para los pequeños receptores del TO en lengua inglesa?

\subsubsection{Domesticaciones}

Las naturalizaciones o domesticaciones del TO tienen lugar, muchas veces ${ }^{17}$, como resultado de una actitud paternalista en el traductor, que detecta un referente probablemente desconocido en la CM (ej: un área de conocimiento overt) y decide sustituirlo por otro con un significado funcional o pragmático semejante en la $\mathrm{CM}$. Esto es lo que ocurre en la figura I extraída de la obra de Babette Cole, Mummy Never Told Me (2003) y de su traducción española Mamá no me contó $(2004)^{18}$ :

La criatura mencionada en el TO, el «hada de los dientes», no forma parte del elenco de

I7 También es cierto que una norma inicial domesticadora puede ser escogida con fines diferentes al de facilitar la comprensión del texto, como tendremos ocasión de ver en el siguiente apartado.

I8 TO: What does the tooth fairy really look like? TM: El ratoncito Pérez... ¿¿se parece a mi dentista? personajes del imaginario infantil hispano (el coco, el hombre del saco...), si bien es cierto que algunos niños la reconocen después de verla en películas o series norteamericanas. $\mathrm{Su}$ equivalente funcional español sería el Ratoncito Pérez, ${ }^{19}$ como se observa en el TM: ambos recogen los dientes de los niños por la noche (probablemente porque los coleccionan) y, a cambio, les dejan un regalo o una moneda. No obstante, su aspecto es bien diferente: ella es una delicada criatura de fantasía con alas de libélula y él se suele representar como un ratón sabio de aspecto bonachón.

La domesticación parece la estrategia más acertada en este caso (álbum para pequeños lectores, con muy poco texto y en donde cualquier nota explicativa estaría fuera de lugar) y lingüísticamente está bien conseguida. La incoherencia grave en el TM se introduce vía ilustraciones, pues se mantienen las del то: mientras que el niño duerme con un diente a su lado, una figura con pequeñas alas espía, semioculta, detrás de la almohada; en la página siguiente vemos la figura de un dentista enarbolando su instrumental y suspendido

19 El ratoncito Pérez es una creación del jesuita español Padre Coloma, quien inventó la historia hacia I894 para consolar al rey Alfonso XIII (por aquel entonces, de unos 8 años) cuando se le cayó un diente. Pronto el mito se extendió a Hispanoamérica y a países cercanos como Francia o Italia. 
en el vacío gracias a dos alas de libélula. El mensaje del To está claro: no existe el hada de los dientes, sino que el profesional encargado de su cuidado es el dentista. Pero, ¿̇cuál es la lectura del TM, en donde la referencia al hada se sustituyó por la referencia al ratoncito Pérez pero sin cambiar las ilustraciones? La interacción semiótica entre texto e imagen queda suspendida. El ratoncito Pérez no figura por ninguna parte y las alas del dentista pueden resultar graciosas para un niño de la CM pero, desde luego, nunca van a llevarle a pensar en el referente cultural originario subyacente. De esta forma, la traducción se expone impúdicamente como tal y no consigue comunicar con éxito el mensaje del TO a los nuevos receptores de la cultura meta. Como comentábamos en un trabajo anterior (Lorenzo, 20II), esta incongruencia podría haberse solucionado de dos formas distintas:

a) Mediante una estrategia naturalizadora que presente al Ratoncito Pérez como sustituto del «hada de los dientes»; en este caso, habría que informar a la autora/ilustradora y, de aceptar este cambio, habría de preparar (o permitir que se preparase) una nueva ilustración en la que el dentista tuviese cola u orejas en lugar de alas.

b) Mediante una estrategia extranjerizante, recurriendo a una traducción literal de «tooth fairy» por «hada de los dientes», confiando en que la globalización (y, en el caso de los álbumes, las propias imágenes) favoreciese la interpretación del elemento extraño.

\subsubsection{Paternalismos ideológicos}

Pero en ocasiones el traductor soluciona el elemento del to que juzga desconocido para sus pequeños receptores mediante domesticaciones con una carga ideológica adicional. Esto es lo que ocurre en los dos ejemplos siguientes, en donde los traductores apuestan decididamente por una defensa de la lengua y la cultura gallega receptora, que lucha por su supervivencia en un mundo con dos grandes monopolios culturales, 43 el español y el estadounidense.

Observemos detenidamente la traducción gallega del siguiente fragmento de Charlie and the Chocolate Factory (Roald Dahl, 196r) (Charlie e a fábrica de chocolate, traducción de Alberto Avendaño de 1996):

[CONTEXto: la siguiente canción pone de manifiesto (con tristeza) el cambio en el ocio de los niños, comparando lo que hacían antaño con sus hábitos al llegar la televisión]

THEY.... USED... TO READ... READ!

They'd READ and READ, AND READ and READ, and then proceed TO READ some more. (...)

The younger ones had Beatrix Potter With Mr Tod, the dirty rotter, And Squirrel Nutkin, Pigling Bland, (...)

So please, oh please, we beg, we pray, Go throw your TV set away, (...) (p. I73)

¡SOÍAN... LER!

LÍAN E LÍAN

LÍAN todo o día

e despois de ler

outro libro querían ver (...)

Historias que agora os nosos nenos

xa poden ler en idioma galego (...)

Con que pregamos, por favor

que se poña fóra o televisor (...) (p. I49)

En el TM se han sustituido los autores y personajes de la LIJ inglesa por una referencia general a la posibilidad de leer en gallego, ya que en el momento en que se publica la traducción se está construyendo el sistema de LIJ gallega, con obras originales y traducidas y es preciso transmitir este hecho a la sociedad y recomendar la lectura de estos textos. 
Volviendo a la traducción de Pongrwiffy and the Goblins' Revenge, también en ella podemos ver cómo la traductora permite que la $\mathrm{CM}$ «se asome» en su texto: todas las escobas del To, con nombres propios relacionados con especies arbustivas (Little Elmer, Ashley, McPine...), son rebautizadas en el TM mediante una estrategia semejante (Inés Pereira, Timoteixo, Anabeto $^{2 \circ} \ldots$ ); pero además, en dos casos ha incluido alusiones a figuras de renombre en Galicia, al escritor Álvaro Cunqueiro (Álvarocoqueiro ${ }^{2 I}$ ) y al político Camilo Nogueira (Caminogueira ${ }^{22}$.

Este tipo de paternalismos que hemos llamado «ideológicos» no solo surgen aprovechando un elemento desconocido del To que merece explicación (o sustitución por otro). A veces los traductores los incluyen de manera adicional, creando texto, como observamos en la traducción gallega de Peter Pan (J.M. Barrie, I9rI), realizada por Alberto Avendaño y publicada en 1989; ofrecemos también, a efectos comparativos, la versión española de Nazaret de Terán (2000):

[Contexto: Wendy actúa como una madre para sus hermanos y para los niños perdidos] то: ...Wendy, though glorying in having them all home again safe and sound... (p. 103)

TM (gallego): ...Wendy, que é das que sente nace-la herba, aínda que estaba encantada de telos a todos sans e salvos de novo na casa... (p. II4)

TM (español): ...Wendy, aunque se regocijaba de tenerlos a todos de nuevo en casa sanos y salvos... (p. 108)

En esta traducción Avendaño introduce una frase hecha (con el significado de 'ser muy lista, ser muy aguda') que no estaba en el To y así pre-

\footnotetext{
20 «pereira» > «peral»; «teixo» > «tejo».

2I «albaricoqueiro» > «albaricoquero»

22 «nogueira» > «nogal»
}

tende contribuir a dinamizar este tipo de léxico (refranes, frases hechas...), que cada vez parece más ajeno a los usos lingüísticos de las nuevas generaciones de gallegos. La lengua gallega es una lengua minorizada inmersa todavía ${ }^{23}$ en un doble proceso de normalización y normativización que precisa fortalecer no solo su literatura ${ }^{24}$ sino también sus propios subsistemas lingüísticos.

Está claro que estos intervencionismos ideológicos son los más polémicos y que implican partir de un posicionamiento de co-autoría creativa en las traducciones, en la línea de lo defendido por Hernández-Sacristán (1994), Wilss (1996) o Schöckel (1997) y más recientemente por Lathey (2006) para el ámbito de la LIJ. Actuaciones como las que acabamos de comentar muestran a unos traductores que «tutorizan» la recepción, convencidos de que el arte de traducir no tiene por qué estar reñido con una función adoctrinadora (añadida por ellos mismos) que intente transmitir determinados valores culturales y evite su desaparición. Las palabras de Marilar Aleixandre (2007: 642), traductora al gallego de uno de los libros de Harry Potter, no dejan ningún lugar a dudas sobre su postura combativa ante presiones de otros sistemas: «Obrigar aos rapaces e rapazas galegos a ler os nomes en inglés parece unha mostra máis da colonización de Europa pola industria cultural estadounidense, ante a que quizais teñamos que deseñar posibles formas de resistencia».

${ }^{23}$ La problemática de la lengua gallega ha sido apuntada hace tiempo por muchos investigadores (cfr. González Millán, I995 o Noia Campos, 1995) y su normalización/normativización sigue siendo, a día de hoy, una asignatura pendiente (Álvarez Lugrís, 20I3: I3).

${ }_{24}$ He aquí el porqué de la publicación de muchas traducciones, que incrementarán el corpus de obras de LIJ a disposición de los lectores 


\subsubsection{Paternalismos para superar falta de} habilidades $y$ discapacidades

Cuando los receptores primarios son niños pequeños o discapacitados los textos han de recibir un cuidado especial. Sin embargo, no siempre sus autores son conscientes de ello. Así, los guionistas de la Blancanieves de Disney (y el resto de participantes en el control de calidad) pasaron por alto un detalle importante cuando presentan en pantalla el paso del tiempo que sigue al envenenamiento de la princesa. La escena está muy bien trabajada estéticamente, con la rama de un árbol cambiando según las estaciones y, sobre ella, un texto que resume lo acontecido en ese tiempo:

TO: ...so beautiful even in death that the dwarfs could not find it in their hearts to bury her... TM: ...they fashioned a coffin of glass and gold, and kept eternal vigil at her side (...)

Pero, ¿¿qué ocurre con los pequeños espectadores que todavía no sepan leer? Los cambios estacionales reflejados en la naturaleza pueden ayudarles a comprender el paso del tiempo, pero no lo que pasó con la princesa y los enanos. Esta "desconexión» se evita en el doblaje español, en donde se ha introducido una voz en off de narrador que lee los textos de pantalla.

Otro ejemplo de traducción paternalista con un claro objetivo didáctico lo tenemos en

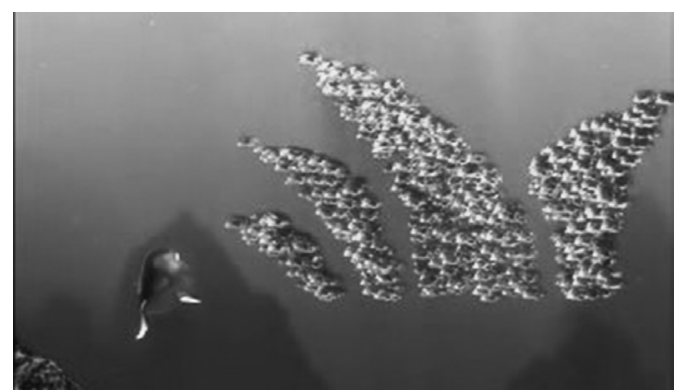

Figura 2 el siguiente fragmento del doblaje de Robots (2005) al español:

[contexto: Manivela defiende a Rodney de los otros robots, que quieren ser reparados] то: Back off, back off.

TM: Vade retro, atrás.

Como podemos apreciar, la opción del doblaje aúna perfectamente la transmisión adecuada del mensaje (se entiende lo que pide Manivela) con el papel formativo de los textos de LIJ: el niño entrará en contacto con la locución latina sin problemas, ya que su significado se introduce inmediatamente después.

En esta línea didáctica estamos trabajando también en subtitulación para niños sordos, cuya discapacidad eleva barreras comunicativas difíciles de franquear. En aquellos momentos en que se detecta que puede fracasar la transmisión del mensaje, se introducen subtítulos explicativos. Consideremos el siguiente ejemplo (Finding Nemo, Andrew Stanton et al., 2003) que proponemos para solucionar el desconocimiento más que probable de un referente cultural (figs. 2 y 3 ):

[ConTexto: Marlin, el padre de Nemo, y su amiga Dory preguntan a un banco de peces el camino a Sydney, porque saben que allí se llevaron a Nemo. Los peces adoptan la forma de la ópera de Sydney para indicar que los han comprendido y que sabrán indicarles el camino]

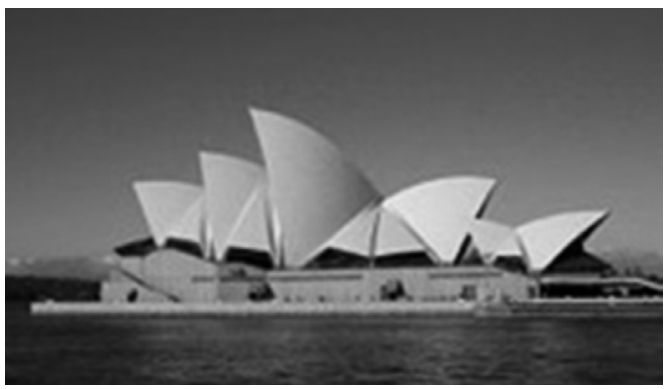

Figura 3 


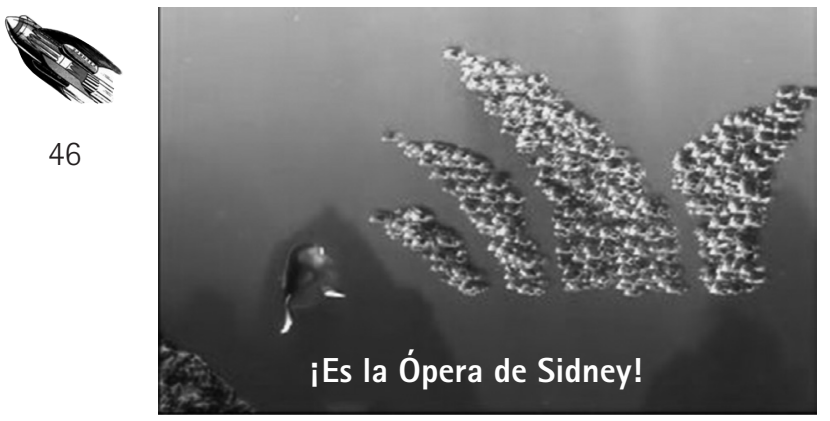

Figura 4

Aprovechando que en estos momentos no hay diálogo, proponemos la introducción de un subtítulo explicativo (figura 4).

Quizás se pudiera pensar que es en exceso paternalista esta forma de proceder y que también habrá niños oyentes que no reconozcan el referente aludido. Cierto. Pero creemos que estas soluciones están plenamente justificadas si comparamos las vías de «conocimiento de mundo» de unos y otros: mientras que los niños oyentes están expuestos desde que nacen a la lengua como refuerzo continuo de la cultura $\mathrm{y}$ adquieren ambas competencias sin esfuerzo, los niños sordos necesitan aprender tanto la lengua oral como la cultura, aprendizaje lento $\mathrm{y}$ arduo que se produce en el contexto escolar y no siempre con los medios más eficaces para conseguirlo.

\section{CONCLUSIONES}

Parece que cuando un texto pasa por el tamiz de los mediadores, sean estos traductores, revisores, ajustadores, directores de doblaje o cualquier otro agente del proceso de trasvase, recibe una atención adicional que probablemente los autores (en el caso de la LIJ) o los guionistas (en el caso de productos audiovisuales de doble receptor adulto-niño) no le habían prestado. Se cuida especialmente al receptor niño y se tienen muy en cuenta tanto sus capacidades lingüísticas como su esperable conocimiento del mundo a la hora de verter el To en el TM. Probablemente el talón de Aquiles de las conductas paternalistas observadas en el trasvase de productos infantiles y juveniles, que ha sido objeto de reflexión en este trabajo, haya que buscarlo en el grado de su aplicación: lograr el punto justo para que dichos intervencionismos "paternales» sean vistos como necesarios para conseguir una traducción comunicativa y no como actitudes que infravaloran los conocimientos de los receptores y restan calidad a la traducción.

RECIBIDO EN DICIEMBRE DE 2013 ACEPTADO EN FEBRERO DE 2014 VERSIÓN FINAL DE DICIEMBRE DE 2013

\section{REFERENCIAS BIBLIOGRÁFICAS}

Aleixandre, M. (2007). «Samaín versus Halloween, cultura e mercancías: nomes na tradución de Harry Potter», en Méndez, L. y Navaza, G. (eds.). Actas do I Congreso Internacional de Onomástica Galega "Frei Martín Sarmiento», Santiago de Compostela: Asociación Galega de Onomástica / Instituto da Lingua Galega, pp. 633-642.

Álvarez Lugrís, A. (20I3). «Elaboración de un corpus para la investigación en T\&I», en Montero, X. (ed.). Traducción para la comunicación internacional, Granada: Comares, pp.3-19.

Aziz Qader, N. (2010). La traducción de literatura infantil español-árabe: análisis traductológico comparado de la obra 'El pirata Garrapata en tierras de Cleopatra', Tesis doctoral inédita, Granada: Universidad de Granada.

Dimitriu, R. (2006). «From Robinson Crusoe to Robinson in Wallachia: The intricacies of the reception process», en Pym, A., M. Shlesinger y Z. Jettmarová (eds.). Sociocultural Aspects of Translating and Interpreting, Ámsterdam: John Benjamins, pp. 73-82.

Even-Zohar, I. (1979). «Polysystem Theory». Poetics Today, I, pp. 287-310. 
- (1997). «Factors and Dependencies in Culture: A Revised Draft for Polysystem Culture Research». Canadian Review of Comparative Literature, XXIV, pp. I5-34.

Fernández López, M. (I996). Traducción y literatura juvenil. Narrativa anglosajona contemporánea en España, León: Universidad de León.

- (2000). «Comportamientos censores en literatura infantil y juvenil: narrativa anglosajona contemporánea en España», en Rabadán, R. (ed.). Traducción y censura inglés-español (1939-1985). Estudio preliminar, León: Universidad de León, pp. 227-254.

Fischer, M. B. (2000). «Diferencias culturales reflejadas en la traducción de la Literatura Infantil y Juvenil», en Ruzicka, V. et al. (eds.). Literatura infantil y juvenil: tendencias actuales en investigación, Vigo: Universidade de Vigo, pp. I49-I6o.

García Martínez, P. (2003). «Censura franquista y traducción para niños. Tres capítulos censurados en Guillermo y el cerdo premiado», en I. Pascua (coord.). Traducción y Literatura Infantil, Las Palmas de Gran Canaria: Universidad de Las Palmas de Gran Canaria, pp. 24I-250.

González Millán, X. (I995) «Cara a unha teoría da tradución para sistemas literarios 'marxinais'. A situación galega». Viceversa, I, pp. 63-72.

Hatim, B. y Mason, I. (I997). The Translator as Communicator, Londres: Routledge.

Hernández-Sacristán, C. (1994). Aspects of Linguistic Contrast and Translation, Frankfurt/Main: European University Studies/Peter Lang.

Klingberg, G. (ed.) (1978). Children's Books in Translation, Estocolmo: Almqvist \& Wiksell.

- (I986). Children's Fiction in the Hands of the Translators, Lund: cwK Gleerup..

Lathey, G. (2006). «The Translator Revealed: Didacticism, Cultural Mediation and Visions of the Child Reader in Translator's Prefaces», en Coillie, J.V. y Verschueren, W.P. (eds.). Children's Literature in Translation, Mánchester: St. Jerome, pp. I-I8.

- (2010). The Role of Translators in Children's Literature: Invisible Storytellers, Nueva York: Routledge.

Lefevere, A. (1992). Translating Literature. Practice and Theory in a Comparative Literature Context, Nueva York: The Modern Language Association of America.

Lorenzo, L. (2003). «Traductores intrépidos: inter- vencionismo de los mediadores en las traducciones del género infantil y juvenil», en Pascua, I. et al. (eds.). Actas del I Congreso Internacional Traducción y Literatura Infantil. Las Palmas de Gran Canaria: Universidad de Las Palmas, 34I-350.

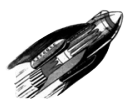

47

- (20II). «Espacios prohibidos y su traducción: Mummy never told me / The Sprog Owner's Manual, de Babette Cole y Scaredy Squirrel, de Mélanie Watt», en Roig Rechou, B-A. et al. (eds.). O álbum na literatura infantil e xuvenil (2000-20I0), Vigo: Edicións Xerais, pp. 395-4II.

Lorenzo, L. y Pereira, A. (2000). "Avoas bébedas rehabilitadas na traducción: A manipulación do texto orixinal para adecuarse ás características do polisistema receptor», en Ruzicka, V. et al. (eds.). Literatura infantil y juvenil: tendencias actuales en investigación, Vigo: Universidade de Vigo, pp. I99-209.

Lorenzo, L. y Ruzicka, V. (2005). «La inmortalidad de Verne en las traducciones. El español como lengua meta», en Roig Rechou, B-A. (coord.). Hans Christian Andersen, Jules Verne e El Quijote na literatura infantil e xuvenil do marco ibérico, Vigo: Edicións Xerais, pp. II7-I3I.

Marcelo Wirnitzer, G. (2003). «Tipos de intervencionismo en la traducción de la literatura infantil y juvenil», en Muñoz Martín, R. (ed.). Actas del I Congreso Internacional de la Asociación Ibérica de Estudios de Traducción e Interpretación. Granada I2-I4 de febrero de 2003, Granada: AIETI, vol. I, pp. 633-639, en línea: <http://www.aieti.eu/pubs/ actas/I/AIETI_I_GMW_Tipos.pdf> [consulta: 7 de octubre de 20I3].

Marrero Pulido, V. (200I). «Información añadida en la traducción literaria, ¿dentro o fuera del texto?», en Pascua, I. (coord.). La traducción: estrategias profesionales, Las Palmas de Gran Canaria: Universidad de las Palmas de Gran Canaria, pp. 69-86.

Merino Álvarez, R. (2000). «El teatro inglés traducido desde I960: censura, ordenación, calificación», en Rabadán, R. (ed.). Traducción y censura inglésespañol, 1939-1985, Estudio Preliminar, León: Universidad de León, pp. I2I-I5I.

Miller, W.J. (2003). The Rehabilitation of Jules Verne in America: From Boy's Author to Adult's Author (19602003), en línea: <http://www.najvs.org/articles/ rehabilitation.htm $>$ [consulta: 9 de octubre de 20I3]. 
Noia Campos, C. (1995). «Historia da traducción en Galicia no marco da cultura europea». Viceversa, I, pp. 13-62.

Nord, Ch. (1997). Translating as a Purposeful Activity, Mánchester: St. Jerome.

Oittinen, R. (2005). Traducir para niños, trad. de Isabel Pascua Febles, Las Palmas de Gran Canaria: Universidad de las Palmas de Gran Canaria.

- (2006). «The Verbal and the Visual: On the Carnivalism and Dialogics of Translating for Children», en Lathey, G. (ed.). The Translation of Children's Literature: A Reader, Ontario: Multilingual Matters.

Pascua Febles, I. (1998). La adaptación en la traducción de la literatura infantil, Las Palmas de Gran Canaria: Universidad de las Palmas de Gran Canaria.

- (2000). Los mundos de Alicia de Lewis Carroll: estudio comparativo y traductológico, Las Palmas de Gran Canaria: Universidad de las Palmas de Gran Canaria.

- (200I). «Alicia en el país de las traducciones: creatividad / literalidad. Dos casos extremos pero reales», en Pascua Febles, I. (coord.). La traducción. Estrategias profesionales, Las Palmas: Universidad de Las Palmas de Gran Canaria, pp. 4I-54.

- (20II). La literatura traducida y censurada para niños y jóvenes en la época franquista: Guillermo Brown, Las Palmas de Gran Canaria: Universidad de las Palmas de Gran Canaria.

Pascua Febles, I. et al. (2003) (ed.). Actas I Congreso Internacional Traducción y Literatura Infantil, Las Palmas de Gran Canaria: Universidad de Las Palmas, pp. 34I-35o.

Ruzicka, V. et al. (1995). Evolución de la literatura infantil y juvenil británica y alemana hasta el siglo XX, Vigo: Ediciones Cardeñoso.

Ruzicka, V. y Lorenzo, L. (2003) (coords.). Estudios criticos de traducción de literatura infantil y juvenil. Tomo I, Oviedo: Septem Ediciones.

Ruzicka, V. y Lorenzo, L. (2008). «A tradución de Literatura infantil e xuvenil en España e a súa situación particular nas comunidades autónomas bilingües». Boletin Galego de Literatura, 38, pp. 97-I2I.

Shavit, Z. (2009). Poetics of Children's Literature, Georgia: University of Georgia Press.

Schöckel, L.A. (I997). «El factor estilístico en la traducción», en Félix Fernández, L. y Ortega Arjonilla, E. (coords.). Lecciones de teoría y práctica de la traducción, Málaga: Universidad de Málaga, pp. $13-24$.

Thomson-Wohlgemut, G. (2006). «Flying High Translation of Children's Literature in East Germany», en Coillie, J.V.y Verschueren, W.P. (eds.). Children's Literature in Translation, Mánchester: St. Jerome, pp. 47-6o.

Toury, G. (I980). In Search of a Theory of Translation, Tel Aviv: The Porter Institute for Poetics and Semiotics.

- (I995). Descriptive Translation Studies and Beyond, Ámsterdam/Filadelfia: John Benjamins.

Shavit, Z. (2006). "Translation of Children's Literature», en Lathey, G. (ed.). The Translation of Children's Literature: A Reader, Clevedon: Multilingual Matters, pp. 25-40.

Zabalbeascoa, P. (2000). «Contenidos para adultos en el género infantil: El caso del doblaje de Walt Disney», en Ruzicka, V. et al. (eds.). Literatura infantil y juvenil: tendencias actuales en investigación, Vigo: Universidad de Vigo, pp. I9-30..

Wilss, W. (1996). Knowledge and Skills in Translator Behavior,Amsterdam/Filadelfia: John Benjamins. 